\title{
Beyond mere information provisioning: a handheld museum guide based on social activities and playful learning ${ }^{1}$
}

Jolien SCHROYEN*, KRIS GABRIËLs*, DANIËL TeUnKEns*, Karel Robert*, KrIS LUYTEN*, Karin CONINX* AND ELKE MANSHOVEN*

\begin{abstract}
During a museum visit, social interaction can improve intellectual, social, personal and cultural development. With the advances in technology, the use of personal mobile handheld devices - such as Personal Digital Assistants (PDAs) - that replace the traditional paper guidebooks is becoming a common sight at various heritage sites all over the world. This technology often leads to problems such as isolating visitors from their companions and distracting visitors away from their surroundings. We believe careful design of mobile applications and taking advantage of low-cost networking infrastructure can avoid such isolation of the visitor from his or her surroundings and encourage interaction with both surroundings and companions. In this paper, we describe our approach to create a mobile handheld guide that supports the learning process by exploiting social interaction between visitors and subtly matching the content and concepts shown on the handheld guide with what can be found in the museum.
\end{abstract}

Keywords: Collaborative learning, social interaction, mobile technologies, mu-seums, PDA.

\section{INTRODUCTION}

ARCHIE is a project in which the educational staff of the Gallo-Roman Museum collaborate with a research team from the HCI group of the Expertise Centre for Digital Media (Hasselt University) in the context of the future expansion of the museum.
The starting point for this interdisciplinary collaboration is our strong belief that a handheld museum guide is a promising medium to enhance the visitor's learning experience.

Recently, the introduction of handheld computer guides into museums has added another dimension to the experience of visiting a museum. PDA technology allows the dynamic 
presentation of information, without disturbing the physical space or being limited by the aesthetics of the galleries. These screen-based multimedia systems also provide opportunities to access multimedia, visuals, photo, video, text and audio while walking through the exhibitions. The first PDA-based applications in museums combined all these advantages, but they also revealed some important shortcomings: the device demands a lot of attention, tends to displace the surrounding objects and generates the unintended side effect that it is quite an isolated, individual experience (Proctor \& Tellis, 2002; Vom Lehn \& Heath, 2005; Vom Lehn, Heath \& Hindmarsh, 2005; Angliss, 2006a, 2006b).

With the ARCHIE project, we want to deal with the above-mentioned unintended side effects and explore the different possibilities a museum guide can offer in the future: a greater versatility for visitors to tailor information to their needs and interests (personalization), to discover the exhibits at their own pace (localization) and to communicate and interact with family or group members (communication).

Though the research on social interaction and collaboration using new technologies is quite recent (Hawkey, 2004), there are already some projects on museum co-visiting. The Sotto Voce project developed an electronic guidebook prototype that promotes interaction between museum visitors through content and audio sharing (Woodruff, Aoki, Hurst \& Szymanski, 2001). This study resulted in an interesting set of design principles, but the collaboration between companions is maybe a little too passive (following or checking in tasks). The goal of the Cicero Project promote social interaction between visitors through cooperative and educational games - fits in with our project (Laurillau \& Paternò, 2004; Dini, Paternò \& Santoro, 2007). Also the reported findings of the user tests of the 'Mystery in the Museum' game in the Solomos Museum are very interesting (Cabrera et al., 2005). However, we hope to take the idea of a collaborative learning activity one step further than the above-mentioned edugames, which still have to be played at a quite individual level, with only a shared enigma.

In this article, we present the ongoing AR$\mathrm{CHIE}$ project and its objectives. One of the main objectives, stimulating social interaction by making use of mobile networked devices, will be thoroughly discussed throughout this text. The remainder of this article is structured as follows: section 2 describes the importance of social interaction and the influence of the context of use on the learning experience during a museum visit. Next, section 3 gives an overview of the software system used as a framework to create mobile applications that support our objectives. Sections 4 and 5 describe two cases being developed on top of our software system. Section 4 provides a concrete insight into how the system works, and how it is being received by our test groups, while section 5 looks ahead and describes a case that is in an initial prototyping phase. Finally, this article is concluded with a short summary of the results obtained.

\section{THE IMPORTANCE OF SOCIAL INTERACTION AND CONTEXT}

"The central fact about our psychology is the fact of social mediation. Higher mental functions in the individual have their origins in the social life of the individual" (L.S. Vygotsky in Falk \& Dierking, 2000, 37).

With this quotation, Falk \& Dierking want 
Jolien Schroyen, Kris Gabriëls, Daniël Teunkens, Karel Robert, Kris Luyten, Karin Coninx and ElKe Manshoven

32 to stress the fact that people make sense of the world through social interaction with others, through distributed meaning-making. "For learning, particularly learning in museums, is a fundamentally social experience" (Falk \& Dierking, 2000, 38). Since learning also constitutes the main reason why people attend museums (Falk \& Dierking, 2000 and Provincial Gallo-Roman Museum, 2005), it is clear that social interaction must be taken into account when designing an educational mobile handheld guide.

Starting from a social-constructivist approach, Falk \& Dierking created their contextual model of learning in museums, in which three interweaving contexts contribute to and influence the interactions and experiences that visitors have with objects and the consequent learning and meaning-making (see figure 1 ). In time, the learning and meaning-making that evolves from these overlapping contexts gets fitted in with both previous and subsequent impressions and knowledge to create a very personal, interactive learning experience.

The main objectives of the ARCHIE project join in with this contextual model of learning. In the following section we give an overview of these objectives.

\subsection{Personal context}

The personal context takes into account what personal background the visitor or learner brings to the learning experience: his or her interests and personal motivation, preferred learning style, prior knowledge and previous experiences. Within the ARCHIE project, we recognize the fact that each visitor is different (age, level of knowledge, interests, etc.) and that these differences influence the way visitors perceive information and are willing to interact with it. While most traditional mobile museum guides often offer a tour and presentation that is the same for all visitors, we want to discover the opportunities and benefits of a personalized approach.

On the highest level, multiple graphical user interfaces are provided, which all have access to the same content but provide a different presentations and are different in the way the visitor interacts with them. We refer to these interactive presentations as interface "shells". One shell is oriented towards adults, who are generally less inclined to engage in playful learning. It contains a means for finegrained personalization, as will be explained in the next paragraph, and since less social interaction is expected from the target group, it only offers some basic options to do so. The second shell offers a collaborative and playful learning experience and is developed with youngsters in mind. Here, identification with the overall museum story is an important issue to get these visitors involved. We try to accomplish that by - among other things - letting them create their own personal avatar that will accompany them throughout the collaborative museum game. Section 3 will elaborate on the structure of the shells and will explain how they are actually built upon the same foundations and are seamlessly interchangeable.

The fine-grained personalization that is implemented in the interface for adults involves rating a whole set of content in terms of topic, presentation and target audience, followed by picking the most appropriate one. Since it is not practical to have a visitor fill in a survey before starting the actual visit, our system starts out with a specific, typifying user profile, which will be adapted slightly during the visit. Similar to the PEACH project, user pre- 


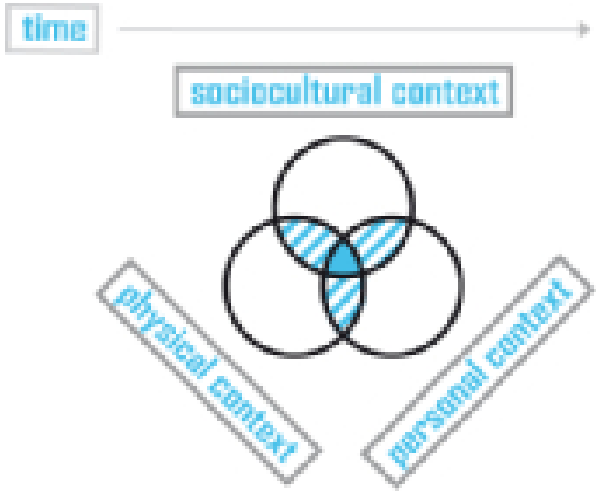

Fig. 1. The contextual model of learning (Falk \& Dierking, 2000).

ferences are extracted while the user interacts with the system (Rocchi, Stock \& Zancanaro, 2006). Our approach does not expect the visitor to give scores for each item, but observes the actions of the user, which can lead to minor modifications to the user profile, which in turn triggers a recalculation of all the content, resulting in some content taking a more prominent place on the screen of the mobile device. This is similar to what is described in $\mathrm{Ku}-$ flik et al. (2005), even though our system does not contain a very extensive user modelling component.

\subsection{PHYSICAL CONTEXT}

The physical context refers to the design and architecture of the museum environment: orientation, construction and lay-out of the exhibit, display of the objects, etc. We take the physical context into account in two different ways. First, we use indoor localization to detect which objects are in the vicinity of the visitor. When the visitor approaches an object or area of interest, a notification will be sent via the mobile device, and the appropriate presentation will be loaded. Another application of indoor localization is tracking the trail followed by the visitor, which can be used to learn about the user preferences or in what areas of the museum the visitors wander around for a long time.

Second, instead of displacing the surrounding objects - as noted above, a common problem with the first PDA-applications - we take into account the various possible interactions between visitors, PDA and museum. This serves as a basis for the design of the presentations on the mobile device. For example, the information presented by the mobile device is dependent on the location of the visitors and what can be perceived in the physical world, but also on the location of fellow visitors. This stimulates interaction between companions. If visitors are at different locations in the museum, the PDA will act as a communication channel between them (see section 3).

\subsection{SOCIO-CULTURAL CONTEXT}

The socio-cultural context accounts for the socio-cultural mediation and facilitation of learning in museums. The ARCHIE project devotes itself to encourage and stimulate interaction between visitors by use of the PDA. As mentioned above, user studies of the first handheld guides in museums stress on the fact that the PDA generates a quite isolated, individual experience (Vom Lehn \& Heath, 2005; Vom Lehn, Heath \& Hindmarsh, 2005; Angliss, 2006a, 2006b). Concerning the predecessor of the PDA, the audio-tour, Angliss (2006a) suggests that "audio can also put individual visitors in a bubble, making it difficult for them to keep track of companions 
Jolien Schroyen, Kris Gabriëls, Daniël Teunkens, Karel Robert, Kris Luyten, Karin Coninx and ElKe Manshoven

34 or family members, let alone chat about what they have seen" (p.47). This remark also applies to PDA-based museum visits and indicates an important obstacle in the use of these new technologies in museums. After all, most people do bring along companions to a museum and try to synchronize their visit with each other. Museum-going is a social event: a day trip for the whole family or for a group of friends. Companions want to share their experiences with each other and talk over their impressions. Furthermore, as we stated before, these conversations between visitors are not only inevitable, they also contribute greatly to their learning experience.

Morrissey (2002) even argues that social interaction not only promotes, but is also a prerequisite for intellectual, social, personal and cultural development. Recent studies with children and object-centred learning also recognize the importance of social interaction: "the potential of the learning environment and its objects largely depends on the social atmosphere generated and the support young children receive through positive, reciprocal interactions. [...] The successful learning setting functions as a community of learners, where all individuals are respected, their learning is supported, and opportunities for collaboration are provided" (Piscitelli \& Weier, 2002, p. 126). An extensive investigation among visitors and potential visitors to the Gallo-Roman Museum confirms these findings (Provincial Gallo-Roman Museum, 2005).

\section{SYSTEM OVERVIEW}

In line with the Falk \& Dierking model, the ARCHIE Mobile Guide System consists of a set of three core services (personalization, localization and communication) on top of which an arbitrary interface shell can be de- ployed (see figure 2). The interface shell can be developed quite independently: it only has to handle events sent by the services it has signed up for. This approach results in a flexible mobile guide system rather than one particular mobile guide. When deployed on multiple devices, the interface shells can be linked together by using the communication service, which handles the interaction between devices, making it possible to create networked applications such as collaborative games.

Figure 2 shows two interface shells, which are currently being implemented as part of the ARCHIE project: the game shell, designed for youngsters, which includes a collaborative trading game, and the informative shell where adults can browse the virtual museum space by manipulating the time-line on their screen. These shells may look like two completely different mobile guides, but they are both built on the ARCHIE core services.

Since one of the main interests of the AR$\mathrm{CHIE}$ project is interaction between visitors and the museum, we will have a deeper look at the communication service. A server application keeps track of the different groups of visitors. During the visit, the system allows visitors to communicate with other visitors in the same group in two different ways:

- a direct communication style that is voicebased and uses Voice-over-IP (VOIP). This allows the visitor to address the other members of the same group directly.

- an indirect communication style that allows visitors to exchange other types of data related to the interface shell. Through collaborative games, experiences and opinions can be shared. The synchronization between different clients involved in a collaborative game depends on the game and should be taken care of by the developer of the shell. 


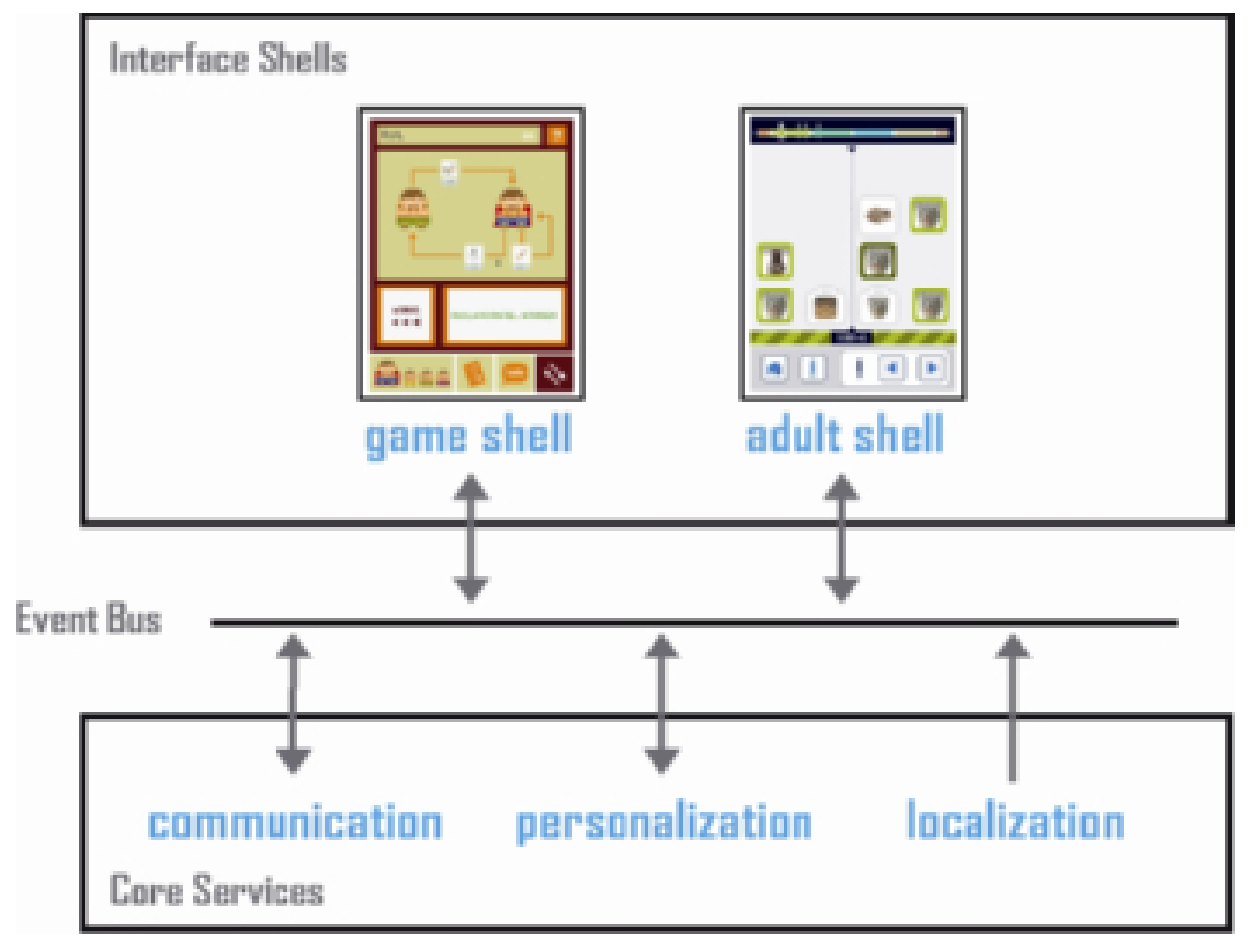

Fig. 2. Framework overview.

Both types of communication make use of the wireless network deployed inside the museum, which covers the complete museum surface that can be visited.

We strived for a low-cost solution and used standard networking components that can be bought at reasonable prices. Wireless access points are used to create the networking infrastructure. Each access point is connected to the central server using a wired LAN connection. Although the system makes extensive use of the wireless network, it does not require a high-performance network infrastructure.

We will elaborate further on the core services in the case study below, covering the collaborative trading game we developed.

\section{CASE STUdY: A COLLABORATIVE TRADING GAME}

To describe our efforts to stimulate learning through interaction, we will discuss a prototype application we designed to create a collaborative learning activity for school groups (aged 10-14 years). In 2006, a collaborative trading game for teams of 4 persons was developed. In collaboration with the educational staff of the museum, we decided to work on a specific chapter of the future museum narrative concerning the introduction of social differentiation in society (round $825 \mathrm{BC}$ ). The main message is the introduction of iron and salt in daily life, which results in new exchange net- 
Jolien Schroyen, Kris Gabriëls, Daniël Teunkens, Karel Robert, Kris Luyten, Karin Coninx and Elke Manshoven

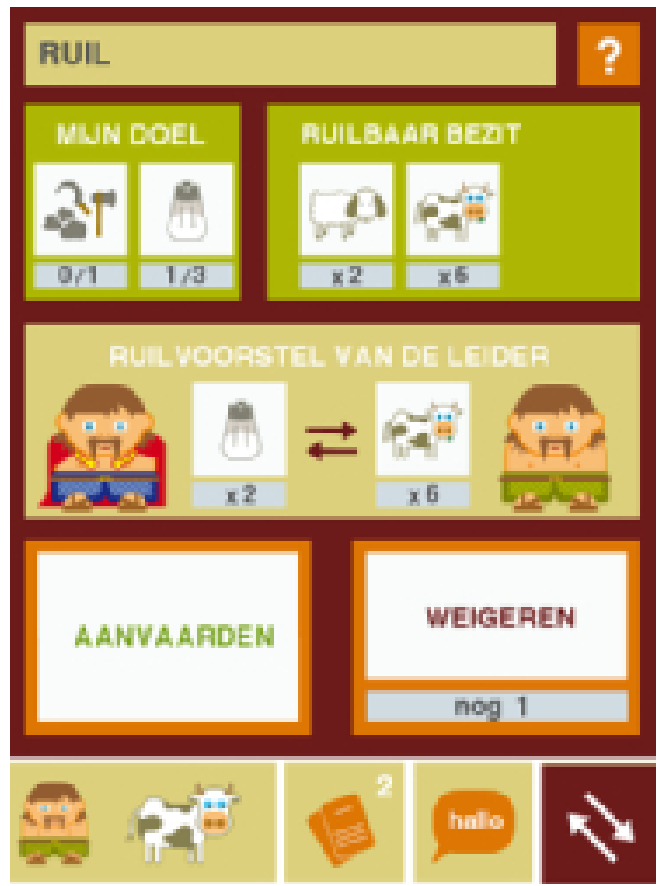

Fig. 3. Trade proposal from leader

works and the emergence of a new élite class as key figures in these contacts.

Every player has an explicit role in the game: there are three farmers and one leader. Each one has his own properties and specific goals that need to be achieved. The game sets off when the three farmers try to solve a set of questions about the exhibits. With every right answer, the farmer gains exchangeable goods (local products such as cattle, sheep, etc.).

The leader has an overall view regarding the exchangeable goods earned, and can make a trade proposal to a farmer. Figure 3 shows a screenshot of one of the farmers getting such a trade proposal from the leader. The upper left of the screen shows the goal of this farmer in terms of a quantity of iron and salt. The upper right shows the exchangeable goods the farmer has gained. In the middle, the leader offers a trade proposal to the farmer (2 salt for 6 cows), which the farmer can either accept or refuse. Only the leader has exclusive contacts in the exchange networks: he can travel to the south three times to exchange the local products for iron and salt. While every farmer has a specific amount of iron and salt as a goal, the leader's objective is to keep every farmer satisfied (this means making sure that every farmer achieves his goals) and to get hold of a bronze sword. The leader profile in figure 4 gives an overview of the accomplishment of his goals ("doel 1" and "doel 2"). The farmer of the waterside region ("zee") has received half of his iron and salt and smiles. The other two farmers still look rather glum (no iron and salt yet: their tub is empty!). The leader has obtained two out of three parts of his bronze sword.

We designed the game in this way so that every player is dependent on the concrete actions of other players. It is only through social interaction and cooperation that they can come to a good end. The main message is to learn in a sub-conscious way about unequal stratifications in society, how they came to existence, how they functioned and more precisely how it must have felt to be in an unequal position. It is exactly this feeling the visitors experience when playing the game because of the unequal amount of influence each player has when participating in the game.

The game is actually an interface shell that is developed on top of the ARCHIE framework and makes use of its several core services. The localization service is used for determining when the game has to be started, namely when all team members are near the physical presentation of the museum narrative concer- 


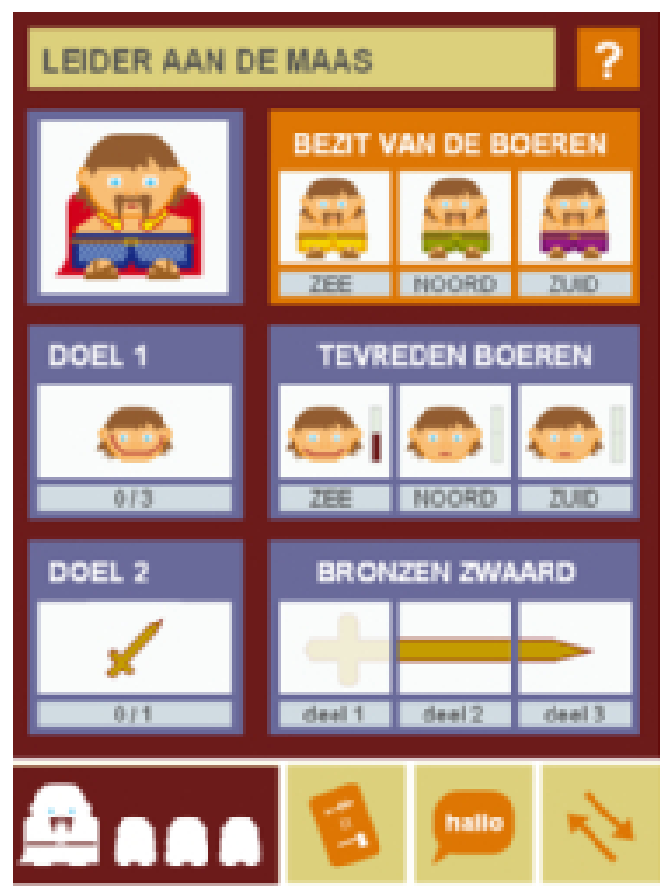

Fig. 4. Leader profile

ned. This is achieved by catching and interpreting the events from the localization service. Personalization is achieved by assigning each team member a specific role - farmer or leader - and by providing each person with his own adapted character or avatar. The communication service makes it possible for teammates to communicate directly to each other via a chatbox. They can use this Voice-overIP-based communication channel to negotiate or comment on the trade proposals and/or to help each other solving the questions. Indirect communication is carried out by the trade actions, which are necessary to accomplish the game. By sending a trade proposal to a farmer, the leader initiates indirect communication. The farmer replies by accepting or refusing this trade proposal. The data that is exchanged between the players is obviously game-related.

In November 2006, the prototype of the trading game was ready for testing and evaluation. We visited three secondary schools in Hasselt and Genk: two general schools and one technical. In all, approximately $70 \mathrm{stu}-$ dents, aged 12 to 15 , tested the prototype in a class room, decorated with posters of museum objects and information to simulate a museum gallery. During the test, the students were observed and afterwards they were asked to fill in a questionnaire concerning personal background, usability and playability of the trading game. As expected, most of the youngsters were familiar with ICT. $78 \%$ of them use a computer on a daily basis, $76 \%$ the Internet and $63 \%$ a mobile phone. As a result, these students were not put off by trying out a new ICT application. Although $80 \%$ of the students declared that they had never used a PDA before, $82 \%$ said it was very easy to use.

In general, the students enjoyed playing the game. A remark often heard was that the game should last a bit longer. Moreover, the questionnaire showed that it was not 'just' a fun game: $75 \%$ answered the questions about content correctly. Furthermore, our evaluations showed the participants understood the unequal stratification in society by playing the game although it was never mentioned explicitly.

In this paragraph, we will focus on aspects of the evaluation of the prototype concerning social interaction and collaboration between the students and interaction with the surroundings. First of all, the chatbox service was positively evaluated: $88 \%$ would certainly use it during a museum visit. Observations showed that the chatbox was used by all participants during the game. In the first instance, the stu- 
Jolien Schroyen, Kris Gabriëls, Daniël Teunkens, Karel Robert, Kris Luyten, Karin Coninx and ElKe Manshoven

38 dents used it for experimenting with this new technology and thereafter to pass on game-related information. The farmers commented on the proposals from the leader and spurred him/her on to trade with them. The test setting in a rather small room in comparison to a museum floor did not allow us to test the use of this application in the way we intended: to support and stimulate communication between visitors who are not at the same location. In the following prototypes, we will reserve the use of the chatbox in particular to games where the players have to swarm about a huge museum floor and cooperate to achieve their goal. Using the chatbox in this context can clearly contribute not only to the enhancement of social interaction during a museum visit, but also to the learning activity.

Concerning the interactions between the players and the museum exhibits - the information posters on the walls - we can state that there was generally a good balance between looking at the screen and looking around. Exceptionally, one team did not automatically look around to examine the museum, even though the PDA explicitly asked them to. The provisional test setting probably did not invite these students to explore their surroundings because of the limited space that was available. We expect that this problem will not occur when the game is played in the actual museum environment that is more suited for exploration.

The observations certainly confirmed that the game provoked collaboration and social interaction among its players. A great deal of these interactions related to the leader role in the game. Although there was an introduction movie explaining the goals and the operating procedure, the leader needed further explanation. The questionnaire confirmed these ob- servations: 9 out of 17 leaders asked for clarification, while only 1 out of 50 farmers stated that he did not understand the introduction movie. The timing also shows a gap between farmers and leader. The average farmer needed about 9 minutes to answer his questions, whereas it also took about 9 minutes to receive his first trading proposal from the leader. The farmers then tried to summon their leader to trade with them. The students clearly did not experience this as a big problem, but we still have to take this into account in future designs. We noticed youngsters do not read onscreen, nor listen to long audio captions, which confirms our idea that it is important to work more visually and to make it more appealing to avoid long introduction instructions. We should also take great care regarding the difficulty of the tasks we offer: they should be sufficiently challenging, intuitively designed, and the different roles should be in harmony with one another.

\section{GAME SHELL: PLAYFUL AND COLLABORATI- VE LEARNING}

After developing and testing this first prototype, we started working on the entire interface shell intended for children and youngsters aged 10 to 14 . To get better acquainted with their needs and expectations, we conducted a brainstorm session with four boys and three girls (12 to 16 years) and invited them to think aloud about gaming in a museum. What are their main expectations towards a museum game?

- it has to be lots of fun, with enough challenges and plenty of variety

- promote unconscious learning (young people do not want to get the impression that they are learning) 
- integrate objects in the museum (exhibits) within the game

- provide an adaptable personal character/ avatar

- integrate a help menu within the game

- etc.

We took these remarks, plus the evaluation of the collaborative trading game, into account when designing a game-shell concept, intended to support a one-and-a-half-hour museum visit by the target group. The game shell consists of various independent collaborative games, which each focus on a specific, key chapter of the future museum narrative. These games are tied together by the overall museum story, but each focus on important aspects of a certain time span, covering - in a nutshell - local history from Neanderthal times until the end of the Roman Empire. The games are meant to be played in teams of 3 to 4 youngsters. A uniform graphic design is maintained throughout the entire game shell. Even this graphic design contributes to the learning experience, as it is closely matched to the content of both the game and the museum narrative. Every game is located in a suitable landscape, given the relevant historical place and time. The features of the landscape and the objects in that landscape evoke the historical circumstances (figure 5).

The brainstorm session confirmed our expectation that youngsters are not opposed to learning new things about history in general. However, when visiting a museum they do not always want to be aware of the fact that they are learning. They still associate a museum visit with a passive activity ("observing") rather than with an interactive activity. We tried to meet this concern by carefully and gradually designing the game shell in various ways as an (inter)active and playful learning experience. First of all, to enhance the commitment of the players to the game and to create a personal touch each player gets to adapt his/her own avatar which accompanies him/her throughout the entire PDA tour (figures 6 and 7).

In every game of the game shell, the avatars of a team find themselves in a different historical period, facing a challenge specific to that period. Via these personalised avatars, the players can imagine themselves in the historical circumstances we evoke, and can contribute to a solution. Furthermore, to create a sense of competition between the teams, we developed an overall scoring system in which players can gain points in the different categories 'smart'

\section{Fig. 5. Landscape with personalised avatar and} Roman army.

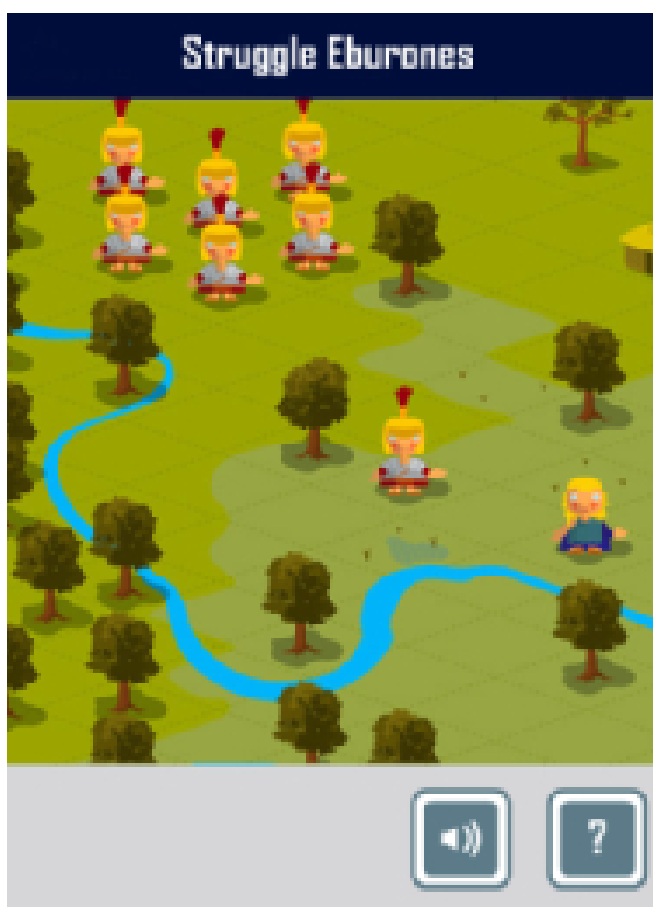


Jolien Schroyen, Kris Gabriëls, Daniël Teunkens, Karel Robert, Kris Luyten, Karin Coninx and Elke Manshoven

\section{choose colour and offprint}
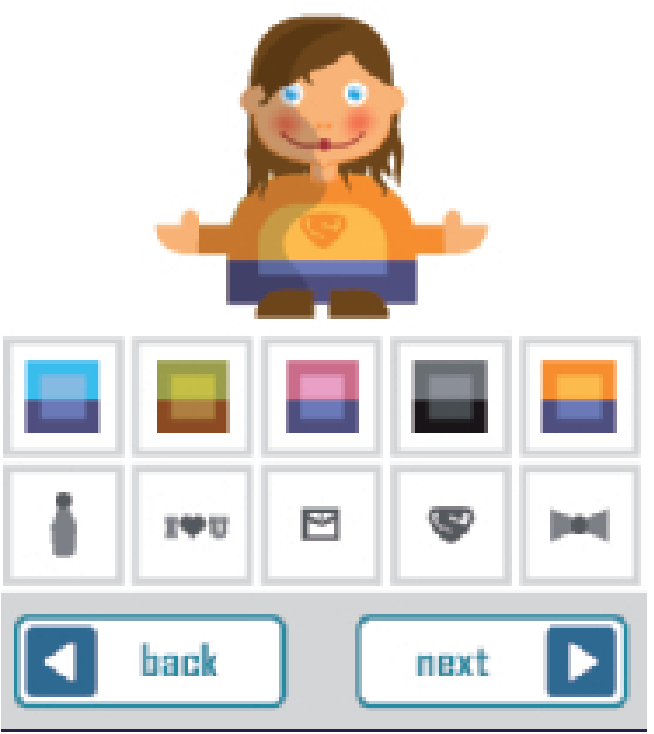

Fig. 6. Adapting personal avatar.

and 'strong' and can obtain a special 'teamwork' bonus. In this way, we induce competition without focusing on one specific point and one specific skill, thus offering different players the chance to excel. Finally, we take great care that the game shell is a playful learning experience and not a history lesson disguised as a game. This is done by avoiding long, dry informative parts and by integrating the museum content fully with the PDA games. We strive for a subtle match between the key messages in the museum narrative and the messages of the games, without explicitly lecturing about any content.

Learning therefore occurs gradually throughout the game shell, without the students being too conscious that they are learning, not only in terms of the messages of the museum narrative but also of skills the students develop during their PDA-based museum visit. Throughout the game shell, the youngsters are challenged to refine skills such as closely observing museum exhibits, cooperating, autonomously exploring the museum, processing information, etc. Each successive game takes the students up to the next level. The players even acquire the skill to use the PDA technology and all its functions gradually, simply by using their interface shell on the PDA. Step by step, more complex functions such as scrolling through a landscape and using the chatbox - are introduced.

We are currently developing a second pro-

Fig. 7. Avatar team.

\section{YDUR TEAM}
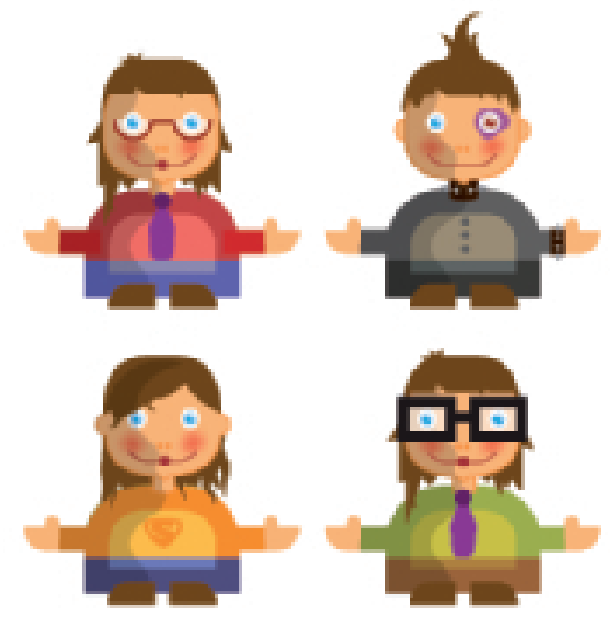

next 
totype application - a collaborative farming game. This game covers the first farming settlement in our region from $5300 \mathrm{BC}$ and onwards. The main message concerns the transition made by these farmers from a nomadic lifestyle to a sedentary one. For the first time in local history, people begin to master their surroundings (grub up trees, for example) to create villages and fields. The players take on the role of early farmers, in search for the ideal starting conditions and the ideal circumstances to ensure a good yield from their fields. To strengthen the impact of this transition from being completely dependent on nature to being able to control and organise their surroundings, the students are now given the opportunity to scroll through the landscape horizontally, whereas in the previous games - situated in nomadic times - the landscape automatically shifted vertically. This is a clear example of how unconscious learning can be stimulated by means of the PDA and the visualisations.

With the difficulties of the trading game in mind, we choose to strive for a less complex and more intensive collaborative activity that also involves face-to-face communication. The students have to exchange the personal information they acquired - via a museum exhibit or via PDA - on the spot to create the best possible location for their farms and fields. Each farmer has his or her specific task to fulfil, but to obtain a good result, the 3 farmers have to cooperate to arrange their shared farming landscape. Farmer 1, for instance, has to grub up trees to make room for the fields (to be positioned by farmer 2) and the farm (to be positioned by farmer 3) (see figure 8). In order to choose the right trees to be cut - so the fertile soil is emptied - farmer 1 needs the information farmer 2 and 3 obtained. Farmer

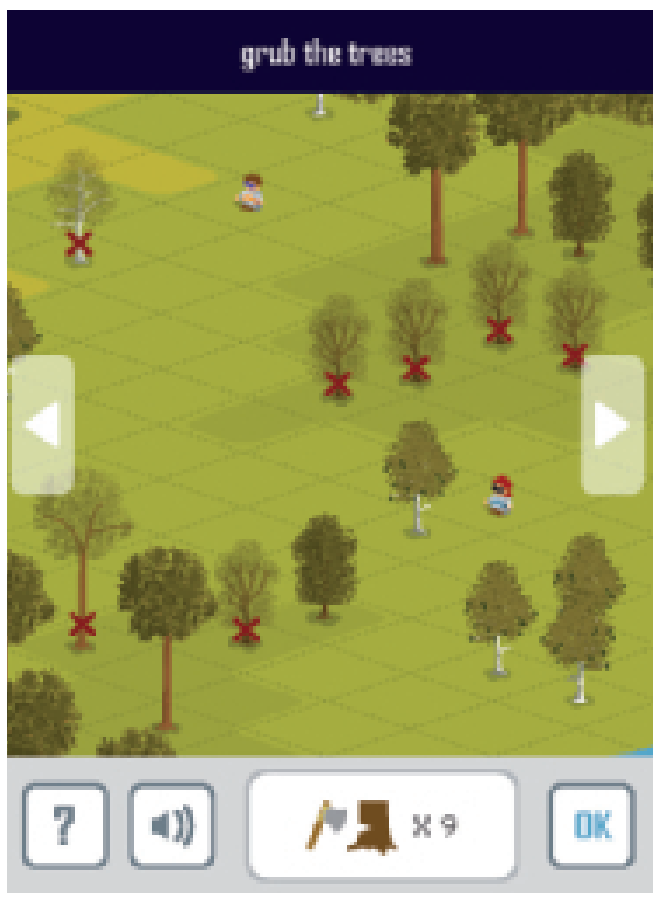

Fig. 8. Task of farmer 1.

2 needs the information of farmers 1 and 3 to know where to situate the fields so they can get as good yields as possible (see figure 9). The players thus have to rely on the information of their team members to make the most profitable decisions.

\section{Conclusion}

In this article, we presented the ARCHIE research project and its objectives. We developed a framework that provides us with the basic services to create a context-aware interactive mobile museum guide that stimulates interaction between visitors and their companions and between visitors and the museum. The basic services included by the framework are 
Jolien Schroyen, Kris Gabriëls, Daniël Teunkens, Karel Robert, Kris Luyten, Karin Coninx and Elke Manshoven

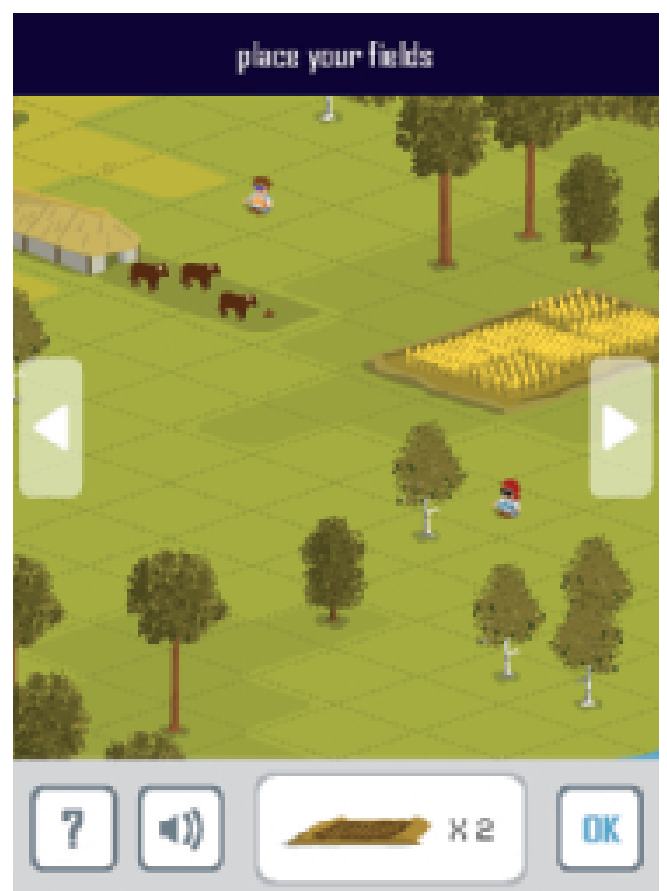

Fig. 9. Task of farmer 2.

location detection, communication between mobile devices and personalization. This framework is used to develop different types of interface shells that are interactive graphical presentations tailored towards a specific target group.

We have developed several interface shells, such as the game shell for youngsters and the informative shell for adults. The trading game was tested thoroughly and the results of these tests are used to steer the ongoing developments, as shown by the farming game that is currently being created. Our approach tries to involve the different target groups as much as possible by means of brainstorm sessions and regular end-user tests. Especially in the game shell, this results in a handheld museum guide that goes beyond merely information provisioning to a playful learning experience, based on social activities.

\section{ACKNOWLEDGMENTS}

Part of the research at EDM is funded by ERDF (European Regional Development Fund), the Flemish Government and the Flemish Interdisciplinary Institute for Broadband Technology (IBBT).

The authors would like to thank Heleen Van Loon who helped lay the foundations of the work presented here and Mieke Haesen who shared her expertise in usability testing and evaluation of interactive mobile applications. We would also like to thank the museum staff of the Provincial Gallo-Roman Museum for close collaboration and the O.-L.-Vrouwlyceum (Genk), Middenschool Kindsheid Jesu (Hasselt) and Technisch Instituut St.-Lodewijk (Genk) secondary schools for evaluating the software discussed in this paper.

\section{Notes}

1. The article is based on a lecture held at the NODEM 06 Conference in Norway, http://www.tii.se/v4m/nodem/index.htm.

\section{REFERENCES}

Angliss, S. (2006a): Talking sense. Museum Practice Magazine, 34, 46-47.

Angliss, S. (2006b): Sound and vision. Museum Practice Magazine, 34, 51-52.

Cabrera, J.S., Frutos, H.M., Stoica, A.G., Avouris, N., Dimitriadis, Y., Fiotakis, G. \& Liveri, K.D. (2005): Mystery in the Museum: Collaborative Learning Activities using Handheld Devices. Procee- 
dings of Mobile HCI 2005, Salzburg, Austria.

Dini, R., Paternò, F. \& Santoro, C.: "An Environment to Support Multi-User Interaction and Cooperation for Improving Museum Visits through Games." In Proceedings of Mobile HCI 2007, Singapore.

Falk, J. \& Dierking, L. (2000): Learning from Museums: Visitor Experiences and the Making of Meaning. Walnut Creek: Altamira Press.

Hawkey, R. (2004): Learning with Digital Technologies in Museums, Science Centres and Galleries. King's College London. Retrieved November 15, 2006, from Futurelab at www.futurelab.org.uk/ research/reviews/09_01.htm

Kuflik, T., Callaway, C., Goren-Bar, D., Rocchi, X., Stock, O. \& Zancanaro, M. (2005): "Non- Intrusive User Modeling for a Multimedia Museum Visitors Guide System.” In Proceedings of User Modeling (UM 2005), pages 236-240, Edinburgh, Scotland.

Laurillau, Y. \& Paternò, F. (2004): "Supporting museum co-visits using mobile devices" in Proceedings of Mobile HCI 2004, Glasgow, Scotland.

Morrissey, K.A. (2002): "Pathways Among Objects and Museum Visitors." In S.G.Paris (Ed.): Perspectives on Object-Centered Learning in Museums. Mahwah: Lawrence Erlbaum Associates.

Piscitelli, B. \& Weier, K. (2002): "Learning With, Through, and About Art: The Role of Social Interactions." In S.G.Paris (Ed.): Perspectives on Object-Centered Learning in Museums. Mahwah: Lawrence Erlbaum Associates.

Proctor, N., \& Tellis, C. (2003): The State of the Art in Museum Handhelds in 2003. Retrieved November 3, 2005, from Museums and the Web 2003 at www.archimuse.com/mw2003/ papers/proctor/proctor.html

Provincial Gallo-Roman Museum (2005): Quantitative learning target group research, unpublished findings, Tongeren.

Rocchi, C., Stock, O., \& Zancanaro M. (2006):
Adaptivity in Museum Mobile Guides: the Peach experience, mobile guide 06 , Turin, Italy.

Thom-Santelli, J., Toma, C., Boehner, K., \& Gay, G. (2005): Beyond Just the Facts: Museum Detective Guides, HCI Group, Cornell University. Retrieved January 26, 2006, from Re-thinking Technologies in Museums at www.idc.ul.ie/museumworkshop/

Van Driel, H. (2001): Digitaal communiceren. Amsterdam: Boom.

Vom Lehn, D., \& Heath, C. (2005): Accounting for New Technology in Museum Exhibitions. International Journal of Arts Management, 7(3), $11-21$.

Vom Lehn, D., Heath, C., \& Hindmarsh, J. (2005): Rethinking interactivity: design for participation in museums and galleries, Work, Interaction \& Technology Research Group, King's College London. Retrieved January 26, 2006, from Re-thinking Technologies in Museums at www.idc.ul.ie/museumworkshop/

Vom Lehn, D., Hindmarsh, J., Luff, P. \& Heath, C. (2007): "Engaging Constable: Revealing Art with New Technology." In Proceedings of the SIGCHI Conference on Human Factors in Computing Systems (CHI'2007), pages 1485-1494, New York.

Woodruff, A., Aoki, P.M., Hurst, A.,, \& Szymanski, M.H. (2001): "Electronic Guidebooks and Visitor Attention." Proceedings of 6th International Cultural Heritage Informatics Meeting, Milan, Italy.

\section{DetaILS ABOUt THE AUTHORS}

* Jolien Schroyen

Educational Assistant

jolien.schroyen@uhasselt.be

In 2003 Jolien obtained a master's degree in History at the KULeuven. She also obtained a 
Jolien Schroyen, Kris Gabriëls, Daniël Teunkens, Karel Robert, Kris Luyten,

Karin Coninx and Elke Manshoven

44 teaching certificate and an abridged bachelor degree in Theology and Religious Studies in 2004. In September 2004 she started working as a teacher and a teacher trainer. She began her work as a researcher and educational assistant for the ARCHIE project in April 2007.

Address: Expertise Centre for Digital Media (EDM)

Hasselt University, Campus Diepenbeek

Wetenschapspark 2

BE-3590 Diepenbeek, Belgium

Tel: +32(0) 11268411

Fax: +32 (0) 11268499

*Kris Gabriëls

Computer scientist

kris.gabriels@uhasselt.be

He obtained a master's degree in Musicology at the KULeuven in 2001 where she also completed a teacher training course in 2003. In January 2006 she obtained an additional master's degree in computer science at Hasselt University. Since February she is working as a researcher investigating innovative mobile technologies with applications in cultural heritage. She joined in the ARCHIE project in February 2005.

Address: Expertise Centre for Digital Media (EDM)

Hasselt University, Campus Diepenbeek

Wetenschapspark 2

BE-3590 Diepenbeek, Belgium

Tel: +32 (0) 11268411

Fax: +32 (0) 11268499
*Daniël Teunkens

Computer scientist

daniel.teunkens@uhasselt.be

He obtained a master's degree in computer science in 2000 from Hasselt University. He immediately started working as a researcher at the Expertise Centre for Digital Media. Before joining the ARCHIE project as a researcher in May 2005, he has been involved in a wide range of various research projects where he was responsible for bringing innovative ICT solutions to the end-user.

Address: Expertise Centre for Digital Media (EDM)

Hasselt University, Campus Diepenbeek

Wetenschapspark 2

BE-3590 Diepenbeek, Belgium

Tel: +32 (0) 11268411

Fax: +32 (0) 11268499

*Karel Robert

Graphic Designer

karel.robert@uhasselt.be

She studied Graphic Design at Sint-Lukas in Brussels, where he obtained his master degree in 2005. In the ARCHIE project he translates heritage concepts into concrete visual representations and is experienced creating rich graphical designs for mobile devices with limited screen size. He brings a touch of frivolity to the designs.

Address: Expertise Centre for Digital Media (EDM)

Hasselt University,

Campus Diepenbeek

Wetenschapspark 2

BE-3590 Diepenbeek, Belgium 
Tel: $+32(0) 11268411$

Fax: $+32(0) 11268499$

Kris Luyten

Professor in Computer Science

kris.luyten@uhasselt.be

He obtained a master's degree in computer science at Hasselt University in 2000, before going on to gain a Ph.D in human-computer interaction at Hasselt University in 2004. Since 2006 he is a professor at the same university, where he conducts research into (among other things) model-based interface development, context-sensitive interactive systems and interactive distributed work spaces.

Address: Expertise Centre for Digital Media (EDM)

Hasselt University, Campus Diepenbeek

Wetenschapspark 2

BE-3590 Diepenbeek, Belgium

Tel: +32 (0) 11268411

Fax: $+32(0) 11268499$

*Karin Coninx

Professor in Computer Science

karin.coninx@uhasselt.be

She gained a Ph.D in Information Technology following a study into Human-Computer Interaction in immersive virtual environments. Since 1998 she has worked as a full-time professor at the Hasselt University and in that capacity lectures on various general information technology subjects and specialized subjects relating to man-machine interaction. As group leader of the human-computer interaction group of the Expertise Centre for Digital Media at the
UHasselt, she is responsible for various research projects relating to interaction in virtual environments, mobile and context-sensitive systems, interactive work spaces, user-centred development and the model-based realization of user interfaces.

Address: Expertise Centre for Digital Media (EDM)

Hasselt University, Campus Diepenbeek

Wetenschapspark 2

BE-3590 Diepenbeek, Belgium

Tel: $+32(0) 11268411$

Fax: +32(0) 11268499

*Elke Manshoven

Customer Relations Assistant

emanshoven@limburg.be

She obtained a master's degree and teaching certificate in History at the KULeuven in 1997. She also obtained (among other things) a Public Relations and Communication Sciences certificate from Hasselt University and graduated as a nature guide.

Since 1999 Elke has worked in the Customer Relations department of the Provincial GalloRoman Museum where she helps coordinate the ARCHIE project.

Address: Provincial Gallo-Roman Museum clo Wijngaardstraat 65

BE-3700 Tongeren, Belgium

Tel: +32(0) 12670346 